\title{
Skin Biopsy
}

National Cancer Institute

\section{Source}

National Cancer Institute. Skin Biopsy. NCI Thesaurus. Code C51692.

Removal of a portion of skin tissue, for microscopic examination. 